\title{
Renal Denervation after Symplicity HTN-3: An Update
}

\author{
Alexandre Persu • Yu Jin • Fadl Elmula Mohamed Fadl Elmula • \\ Lotte Jacobs • Jean Renkin • Sverre Kjeldsen
}

Published online: 10 June 2014

(C) The Author(s) 2014. This article is published with open access at Springerlink.com

\begin{abstract}
After three years of excessive confidence, overoptimistic expectations and performance of 15 to 20,000 renal denervation procedures in Europe, the failure of a single well-designed US trial-Symplicity HTN-3 - to meet its primary efficacy endpoint has cast doubt on renal denervation as a whole. The use of a sound methodology, including randomisation and blinded endpoint assessment was enough to see the typical 25-30 $\mathrm{mmHg}$ systolic blood pressure decrease observed after renal denervation melt down to less than $3 \mathrm{mmHg}$, the rest being likely explained by Hawthorne and placebo effects, attenuation of white coat effect, regression to the mean and other physician and patient-related biases. The modest blood pressure benefit directly assignable to renal denervation should be balanced with unresolved safety issues, such as potentially increased risk of renal artery stenosis after the procedure (more than ten cases reported up to now, most of them in 2014), unclear long-term impact on renal function and
\end{abstract}

This article is part of the Topical Collection on Blood Pressure Monitoring and Management

\footnotetext{
A. Persu $\cdot$ J. Renkin

Pole of Cardiovascular Research, Institut de Recherche

Expérimentale et Clinique, Université Catholique de Louvain, Brussels, Belgium
}

\author{
A. Persu $(\varangle) \cdot J$. Renkin \\ Division of Cardiology, Cliniques Universitaires Saint-Luc, \\ Université Catholique de Louvain, 10 Avenue Hippocrate, \\ 1200 Brussels, Belgium \\ e-mail: alexandre.persu@uclouvain.be \\ Y. Jin · L. Jacobs \\ Studies Coordinating Centre, Research Unit Hypertension and \\ Cardiovascular Epidemiology, KU Leuven Department of \\ Cardiovascular Sciences, University of Leuven, Leuven, Belgium \\ F. E. Fadl Elmula $\cdot$ S. Kjeldsen \\ Department of Cardiology, Ullevål University Hospital, University \\ of Oslo, Oslo, Norway
}

lack of morbidity-mortality data. Accordingly, there is no doubt that renal denervation is not ready for clinical use. Still, renal denervation is supported by a strong rationale and is occasionally followed by major blood pressure responses in at-risk patients who may otherwise have remained uncontrolled. Upcoming research programmes should focus on identification of those few patients with truly resistant hypertension who may derive a substantial benefit from the technique, within the context of well-designed randomised trials and independent registries. While electrical stimulation of baroreceptors and other interventional treatments of hypertension are already "knocking at the door", the premature and uncontrolled dissemination of renal denervation should remain an example of what should not be done, and trigger radical changes in evaluation processes of new devices by national and European health authorities.

Keywords Renal denervation - Resistant hypertension . Ambulatory blood pressure $\cdot$ White coat effect $\cdot$ Blinding . Renal artery stenosis

\section{Introduction}

In 2009, Krum and colleagues [1] published a nonrandomised proof-of-concept study, testing percutaneous radiofrequency catheter-based renal sympathetic denervation $(\mathrm{RDN})$ as a novel treatment of resistant hypertension in a cohort of 45 patients. RDN proved feasible, effective (blood pressure decrease: $-27 / 17 \mathrm{mmHg}$ at 12 months) and safe. One year later, the Symplicity HTN-2 investigators confirmed these impressive results in an open-label randomised trial including 106 patients with resistant hypertension. One hundred patients were assessed for the primary endpoint at 6 months: in the RDN group ( $n=49)$, office blood pressure decreased by $32 / 12 \mathrm{mmHg}(P<0.0001)$, whereas blood 
pressure (BP) remained unchanged in the control group $(n=51)(+1 / 0 \mathrm{mmHg}, P \geq 0.77)$. Accordingly, at 6 months the between-group difference in office blood pressure averaged $33 / 11 \mathrm{mmHg}(P<0.0001)[2 \cdot \bullet]$. There were no serious procedure-related or device-related complications and occurrence of adverse events did not differ between groups [2••]. Similar blood pressure decreases were documented 6 months after RDN, both in the Symplicity HTN-1 registry [3] $(-25 / 11 \mathrm{mmHg})$ and a meta-analysis including mostly uncontrolled studies $(-25 / 10 \mathrm{mmHg})[4]$.

Still, in this sunny landscape, many shadows remained. Only a minority of patients with resistant hypertension were found to be eligible for RDN [5, 6, 7•]. Blood pressure response to RDN was highly variable [8]. Besides baseline blood pressure, no predictors of response to RDN were consistently found. In particular, clinical situations associated with sympathetic overactivity such as diabetes, metabolic syndrome or chronic kidney diseases were not associated with an increased likelihood of blood pressure response to RDN $[2 \bullet, 3,8]$. On the contrary: in the European Network COordinating research on Renal Denervation (ENCOReD) registry, baseline plasma creatinine was inversely correlated with blood pressure decrease 6 months after RDN [8]. After exclusion of non-adherent patients, the residual benefit of RDN was minimal [9]. Ambulatory blood pressure decrease after RDN was seldom reported, and when reported was not always significant $[10,11]$. In the largest cohorts where both office and out-of-the office blood pressure were measured, ambulatory blood pressure decrease was only one-third of office blood pressure decrease [8, 12], versus an expected $60-70 \%$ in drug trials $[13,14]$. Finally, the lack of any blood pressure decrease in the control group of Symplicity HTN-2 [2••] was a matter of concern [15]. As a comparison, in three contemporary randomised studies performed in patients with resistant hypertension [16-18], office systolic blood pressure in the control group decreased by 8,9 and $14 \mathrm{mmHg}$, respectively.

As early as 2012, we and others $[13,15]$ have stressed some of these discrepancies, suggesting that part of the apparent benefits of RDN may reflect non-specific effects such as placebo effect, Hawthorne effect, decreasing white-coat effect, regression to the mean and other patient or physicianrelated biases. It was also suggested that the differential outcome between RDN and placebo arms would substantially shrink if assessment of efficacy was blinded, either using 24-h ambulatory blood pressure as primary endpoint $[8,13]$, or a sham procedure $[19 \bullet \bullet]$.

\section{Renal Denervation before Symplicity HTN-3}

Despite these caveats, publication of the Symplicity studies [1, $2 \bullet \cdot 3]$ was followed by an unprecedented wave of enthusiasm. Medtronic Inc ${ }^{\circledR}$ (Minneapolis, Minnesota) paid $\$ 800$ million upfront to purchase $\operatorname{Ardian}^{\circledR}$ (Mountain View, California), the company that had developed the technology [20]. More than ten companies developed their own RDN system, five of which obtained the Conformité Européenne (CE) mark. The procedure was quickly reimbursed in Germany, and later on in Switzerland, Sweden and the Netherlands. While RDN remained an investigational procedure in the US, 15 to 20,000 procedures were performed in Europe in less than 4 years [21••], most of them using the Ardian-Medtronic ${ }^{\circledR}$ catheter. As icing on the cake, RDN was recommended by the European Society of Hypertension (ESH) with a grade IIC recommendation for treating patients with resistant hypertension [22].

Based on mostly small, purely observational studies, RDN was associated with ancillary benefits such as decreased left ventricular mass [23], arterial stiffness [24], heart rate and atrioventricular conduction [25, 26], arrhythmia burden [27], renal resistive indices [28] and albuminuria [29], as well as with improved cardiac function [23], central hemodynamics [24] and insulin sensitivity [30]. Furthermore, it was proposed as a potential treatment in a host of medical conditions, including chronic kidney disease [31], atrial fibrillation [32], heart failure [33], obstructive sleep apnoea [34] and polycystic ovary syndrome [35]. Finally, in spite of cautionary recommendations by European [36] and international [37] expert panels, RDN was applied to patients with white-coat resistant hypertension [12], isolated systolic hypertension [38], stenotic [39] or stented [40] renal arteries and even - inadvertentlyin a patient with Münchausen syndrome [41]. New papers devoted to RDN were published weekly, if not daily, and all top-ranking journals in the field were keen to host studies, reviews and editorial comments addressing this novel approach [20]. In the meantime, dissenting and cautionary advice $[13,15]$ and predictions [19••] remained almost unheard in the general chorus of praise.

\section{The Earthquake of Symplicity HTN-3}

Symplicity HTN-3 [42••], a large US randomised controlled trial including 535 patients assigned in a $2: 1$ ratio to RDN or a sham procedure, was to be the last step of the triumphal march of RDN. Accordingly, the announcement that Symplicity HTN-3 failed to meet its primary efficacy endpoint (http://www.tctmd.com/show.aspx?id=123265) stunned the medical community and device industry as a deep shock, and was quickly followed by definitive or temporary stopping of large ongoing research programmes (http://www.reuters.com/article/2014/01/24/us-covidiendivestment-idUSBREA0N18B20140124). A rapid opinion shift from excessive optimism to deep mistrust ensued [43]. 
In contrast with Symplicity HTN-2 [2••], in Symplicity HTN-3 [42••], the mean decrease in office systolic blood pressure at 6 months was only $14.13 \mathrm{mmHg}$ in the RDN group, as compared with a substantial $11.74 \mathrm{mmHg}$ decrease in the sham group $(P<0.001$ for both comparisons of the change from baseline). This corresponds to a modest $2.39 \mathrm{mmHg}$ advantage in favour of the technique, lower than the preset superiority margin of $5 \mathrm{mmHg}[42 \bullet \bullet]$. Discordant results were also observed for ambulatory blood pressure, particularly in the control group. While in Symplicity HTN2, 24-h ambulatory systolic blood pressure decrease was $11 \mathrm{mmHg}$ in 20 patients treated with RDN ( $p=0.006)$ compared to a non-significant $(p=0.51)-3 \mathrm{mmHg}$ in 25 patients from control group [2••], in Symplicity HTN-3, 24-h ambulatory blood pressure decrease was modest but significant and of the same order of magnitude in both groups $(-6.75 \mathrm{mmHg}$ and $-4.79 \mathrm{mmHg}$, respectively; $p<0.001$ for both) [42••] (Fig. 1).
The huge discrepancy between Symplicity HTN-3 on one side and most other studies including Symplicity HTN-2 on the other side raises concern. Can a single large US trial challenge all previous studies? Who is right? Symplicity HTN-2, Symplicity HTN-3, or both? Compared to Symplicity HTN-2 [2••], patients included in Symplicity HTN-3 [42••] were more overweight (body mass index: 34 vs. $31 \mathrm{~kg} / \mathrm{m}^{2}$ ), at higher cardiovascular risk (slightly higher proportion of type 2 diabetes and dyslipidemia) and took more diuretics ( 99 vs. $89 \%$ ) and aldosterone antagonists (23 vs. $17 \%)$. Furthermore, as expected in a US population, the Symplicity HTN-3 cohort included one-fourth of patients of African descent [42••], while this proportion was negligible in Symplicity HTN-2 $[2 \bullet \bullet]$. The catheter used in Symplicity HTN-3 [42••] was the second generation Medtronic Symplicity catheter rather than the original, stiffer Ardian catheter used in Symplicity HTN-2 [2••]. Finally, as most
ENCOReD_RDN ( $n=109)$

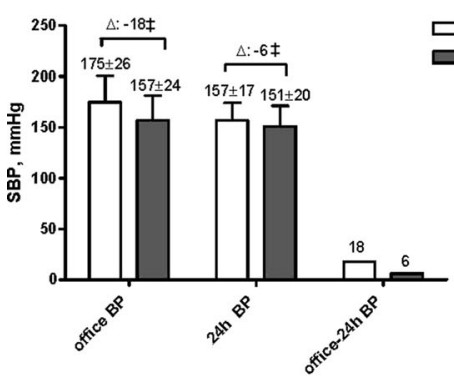

German multicentric cohort_RDN $(n=346)$
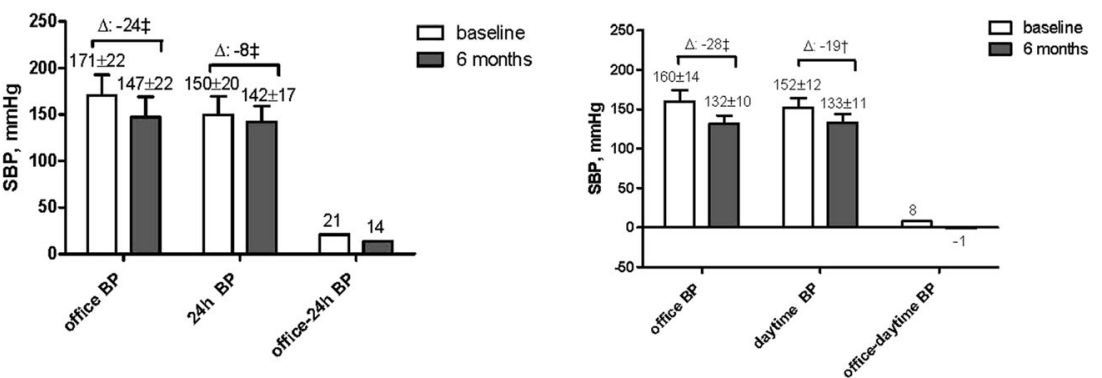

SYMPLICITY HTN-3 RDN group $(n=353)$
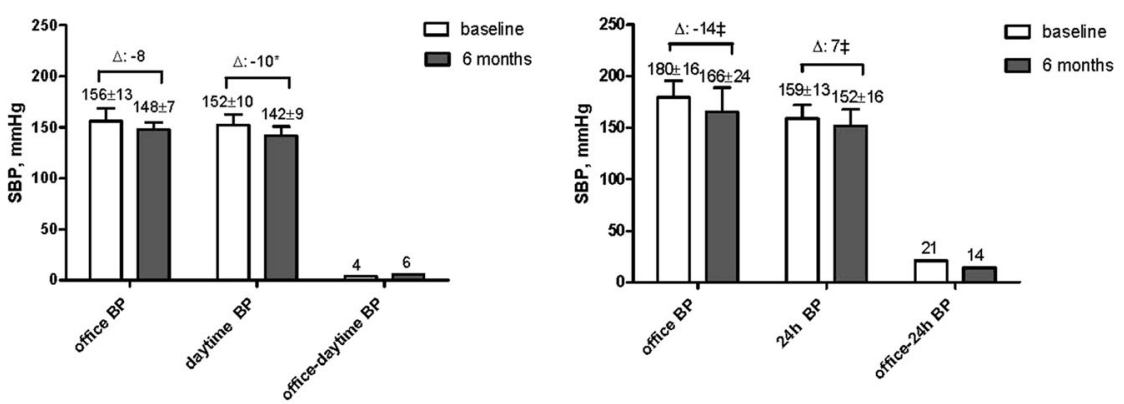

SYMPLICITY HTN-3 sham group $(n=171)$

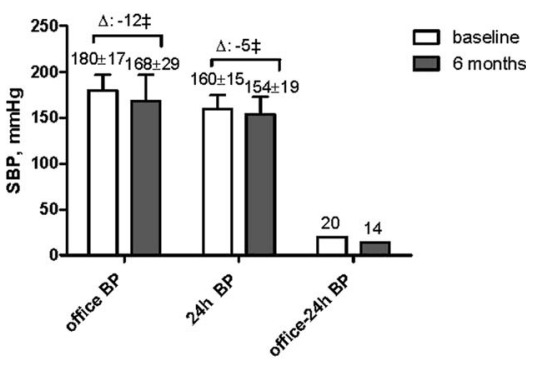

Fig. 1 The figure compares changes in office blood pressure, ambulatory blood pressure and white coat effect (office blood pressure-ambulatory blood pressure) between baseline and 6 months in patients who underwent renal denervation in the European RDN cohort [8], the multicentre German RDN cohort [12] and the Oslo RDN [21] and Symplicity HTN-3 [42] randomised control trials. It highlights the following points: (1) with the exception of office blood pressure in the OsloRDN trial, baseline blood pressures are very similar; (2) while office blood pressure changes largely vary from one study to the other, ambulatory blood pressure decrease is highly consistent, between 6 and $10 \mathrm{mmHg}$; (3) in agreement with our previous analysis comparing blood pressure decrease in the ENCOReD RDN cohort and the placebo and treatment arms of the Syst-Eur trial [8], blood pressure decrease after RDN seems to be intermediary between decreases observed in placebo and drug treatment adjustment groups. However, formal demonstration would require a three-arm randomised trial comparing directly RDN, drug treatment adjustment and continuation of baseline drug treatment; (4) with the exception of the Oslo RDN trial, where baseline difference between office and ambulatory blood pressure was $<5 \mathrm{mmHg}$, white coat effect typically decreased by $18-21 \mathrm{mmHg} 6$ months after RDN, which represents twice the $10 \mathrm{mmHg}$ decrease proposed by the Symplicity investigators to define blood pressure response to RDN; (5) the attenuation of white coat effect at six months was similar in the RDN and placebo arms of Symplicity HTN-3, and larger in the drug adjustment than in RDN arm of the Oslo RDN trial. These observations confirm that the large discrepancy between office and ambulatory blood pressure changes observed in most RDN trials reflects non-specific effects [8] rather than an effect of RDN per se, as hypothesized by Doumas et al. [14]. BP: blood pressure; ENCOReD: European Network COordinating research on Renal Denervation; RDN: renal denervation; SBP: systolic blood pressure 
Symplicity HTN-3 investigators performed their first RDN within the trial, they might have been less experienced that the Symplicity HTN-1 and 2 investigators $[42 \bullet \cdot]$.

The aforementioned differences in study populations and in the RDN procedure itself may partly account for the less important blood pressure decrease in RDN-treated patients from Symplicity HTN-3 [42••] compared to previous studies. However, they cannot explain the most striking difference between Symplicity HTN-2 [2••] and Symplicity HTN-3 [42••]: while in Symplicity HTN-2, blood pressure remained unchanged in the placebo arm, in Symplicity HTN-3 it decreased to almost the same extent as in the RDN arm. The single credible explanation is that Symplicity HTN-3 was blinded, while other studies were randomised but unblinded (Symplicity HTN-2) or purely observational [19••, 42••]. By contrast with Symplicity HTN-3, open-label studies such as Symplicity HTN-2 are subject to expectation, performance and evaluation biases [15]. In other words, knowing to which treatment group participants are allocated may have affected both physicians' and patients' behaviour, particularly if they felt that RDN was the last option available, as implied by the concept of resistant hypertension, if they strongly believed in the efficacy of the technique, or were newcomers in the field of hypertension and blood pressure measurement. Symplicity HTN-2 investigators may have been inclined to measure blood pressure differently in the two groups: for example, the resting period before office BP measurements and the number of BP measurements taken may not have been the same in the RDN and control arms [15]. As detailed elsewhere [13], the Symplicity HTN-2 protocol for blood pressure measurement and recording made this trial particularly vulnerable to such kind of biases. On the other side, being in the RDN group, and as such benefitting from increased attention from the caring physician, may have improved adherence to drug treatment $[13,15,19 \bullet \bullet]$. Conversely, patients from the control arm may have been tempted not to take properly their medications in order to benefit from RDN after assessment of the primary endpoint at 6 months $[13,15]$. In contrast, in a blinded study such as Symplicity HTN-3 [42••], such biases are minimised. In particular, improved adherence to drug treatment is likely to have occurred irrespective of the treatment arm, accounting for part of the substantial blood pressure decrease in the control group [44].

Some of the most enthusiastic exponents of RDN are already ready to "seek redemption" for RDN [45], without fully accepting the lessons of Symplicity HTN-3. While it was previously assumed that RDN was rather easy to perform, they put forward the lack of experience of Symplicity HTN-3 investigators [42••]. They suggest that patients in Symplicity HTN-3 were not the right ones [46] (which is likely, but also applies for previous studies) [47], that selection based — even partly - on ambulatory blood pressure may be inappropriate [46], and that, after all, if RDN is less effective than expected, it may have benefits beyond blood pressure [48] and cure other diseases. However, they forget to tell that these purported benefits are based on observational studies, similar to those that helped to build up the premature success of RDN as an antihypertensive treatment [49]. As for blood pressure, demonstration of benefits of RDN beyond blood pressure can be achieved only within the context of well-designed randomised controlled studies [13]. Notably, while three studies - two based on cardiac echography [23, 48] and one on magnetic resonance imaging (MRI) [50] - suggest a beneficial effect of $\mathrm{RDN}$ on left ventricular structure and cardiac function, 3 years after publication of Symplicity HTN-2, the results of the cardiac MRI substudy at 6 months are still not in the public domain.

The key message of Symplicity HTN-3 [42••] is simple and we should be wise enough to accept it: in patients meeting the entry criteria of the study (and probably those of Symplicity HTN-1 and 2 as well), the true overall benefit of RDN on systolic blood pressure is modest, $<3 \mathrm{mmHg}$, without evidence of a favourable impact on morbidity-mortality thus far. All the rest is common to the placebo and RDN groups, and thus represents "noise", whatever it means. These findings are reinforced by those of the recently published Oslo RDN trial $[21 \cdot \bullet$, stopped early in view of the dramatic superiority of adjusted drug treatment vs. RDN. In view of these results, enthusiastic pharmaco-economic [51, 52] and quality-of-life [53] analyses have collapsed like a house of cards because they are based on weak assumptions. RDN is not ready for clinical deployment and reimbursement is at least questionable.

On the other side, reason takes back her rights. All previous discrepancies are now easily understandable. If the blood pressure decrease observed in previous studies is mostly related to patient and physician-related biases, it is not unexpected that blood pressure outcome may critically depend on the expertise of centres, the way in which blood pressure is measured, and/ or the individual characteristics and psychology of patients. It is obvious that ambulatory blood pressure, which minimises observer-related bias and placebo effect [54], will be much less affected than office blood pressure. Finally, it is not surprising that, besides baseline blood pressure, few consistent predictors of response have been identified $[2 \bullet \bullet, 3,8]$. This is particularly true for Symplicity studies and registry $[2 \cdot \bullet, 3]$. Indeed, in the latter, blood pressure response to RDN was defined as a decrease in office systolic blood pressure of $\geq 10 \mathrm{mmHg}$, which is less than the decrease in white coat effect at 6 months in the ENCOReD [8] and German multicentre [12] cohorts (18 and $21 \mathrm{mmHg}$, respectively), and inferior to the blood pressure decrease in the sham group of Symplicity HTN-3 [42••] (-14 mmHg) (Fig. 1). 


\section{A Closer Look at Safety Issues}

The first announcement of the failure of Symplicity HTN-3 $[42 \cdot \bullet]$ to achieve its primary endpoint was accompanied by a second statement on the fact that the primary safety endpoint was met (http://www.tctmd.com/show.aspx?id=123265). At first sight, this may convey the impression that the Simplicity HTN-3 investigators have achieved at least one of their aims after all, and thus mitigate our disappointment. However, it should be pointed out that the primary safety endpoint - a composite of major adverse events, including death, endstage renal disease, an embolic event resulting in end-organ damage, renal-artery or other vascular complications, hypertensive crisis within 30 days or new renal-artery stenosis of more than $70 \%$ within 6 months [42••] —was an easy target to reach. Indeed, an increased incidence of death or major cardiovascular events after RDN is unlikely and would have been already detected in existing registries. It was also unlikely that RDN would be associated with more hypertensive crisis than in the sham group. Finally, as in previous Symplicity studies $[1,2 \bullet \bullet, 3,55]$, in the absence of systematic computed tomography (CT) or MRI, a substantial proportion of renal artery stenosis may have been overlooked [13].

Up to now, at least 13 cases of significant, de novo renal artery stenosis have been documented 3 to 6 months after RDN performed using four different renal ablation systems $[2 \bullet \bullet, 55-65]$. The diagnosis was made following blood pressure increase after an initial decrease [2••, 56-65], renal function degradation $[59,61]$ and/or repeated pulmonary oedema $[61,63]$. Notably, most of these reports were published in 2014, i.e., after the Medtronic announcement that Symplicity HTN-3 had failed to reach its primary endpoint. Systematic $\mathrm{CT}$ angiography after RDN was performed in only three small cohorts, with a prevalence of renal artery stenosis of $2 / 11$ (18\%) [64]; $3 / 46$ (6.6\%) [61, 66]; and 2/15 (13.3\%) (http://www.tctmd.com/show.aspx?id=120456), respectively. If confirmed on a larger scale, this frequency is not negligible, especially in view of the modest efficacy of the technique [21 ••, $42 \bullet$ ]. It may prove even higher if one includes cases of progression of non-significant baseline stenosis [55, 67], some of which could have been favoured by RDN.

Long-term evolution of renal function is also a matter of concern. While glomerular filtration rate (GFR) at 6 months was similar in both RDN and control groups in Symplicity HTN-2 [2••] and Symplicity HTN-3 [42], in the Symplicity HTN-1 registry [55], eGFR loss at 36 months was estimated to be $9.3 \mathrm{ml} / \mathrm{min} / 1.73 \mathrm{~m}^{2}$, a twofold to eightfold larger decrease than in other contemporary trials including patients at high cardiovascular risk (median follow-up: 29 to 56 months) [68-70]. Whether this evolution reflects the natural history of renal function in patients with severe, resistant hypertension, increased use of diuretics and/or renin angiotensin inhibitors or a deleterious effect of RDN per se remain to be determined.

\section{Conclusion}

Take-Home Messages for Clinical Practice

In patients with resistant hypertension as a whole, the efficacy of RDN has been largely overestimated [42••]. Overall, it is clearly inferior to expert drug treatment adjustment $[21 \bullet \bullet]$. While a minority of patients may show an impressive response to RDN [8], predictors of response are largely unknown $[2 \cdot \bullet, 3,8]$. Accordingly, it is obvious that RDN is not ready for clinical use. Is this news really bad news? Not really. The prevalence of apparently resistant hypertension-i.e., uncontrolled hypertension despite intake of three antihypertensive drug classes - is estimated to be between 3 and $30 \%$ of the hypertensive population [71-73], with figures of less than $10 \%$ probably representing the true prevalence [22]. It may shrink dramatically (below $5 \%$ ) if the definition is restricted to those subjects whose blood pressure remains uncontrolled despite the use of a triple therapy at maximal dosage, including a diuretic [73], and even more when patients with secondary or white coat resistant hypertension (30-40\%) [72] and poorly adherent patients [74••, 75] are excluded. Within the remaining subgroup of "truly resistant" hypertensive patients, a substantial proportion is still amenable to blood pressure control in expert centres [7•].

The proportion of patients in whom RDN appears as the single option is thus very low (probably $<1 \%$ ) $[5,73]$. Furthermore, many of them will not qualify for the procedure due to anatomical reasons [76], or are unlikely to benefit from RDN because of advanced renal failure [8] or increased arterial stiffness associated with older age.

\section{Take-Home Messages for Research}

While, as stated in a recent editorial, the "RDN bubble" has exploded [44] and overoptimistic views have been abandoned, this does and should not mean the end of RDN [43]. Most patients with resistant hypertension are indeed amenable to blood pressure control after skillful treatment adjustment. However, complex drug treatments are not always well tolerated in the long run. Drug adherence is inversely correlated with the number of drugs [77] and steadily decreases over time [78]. Furthermore, complex therapies imply frequent blood samples and medical visits, and are thus costly and time consuming. On the other side, RDN rests on a solid rationale [79]. Most investigators have witnessed at least a few cases of impressive blood pressure decrease after RDN [8]. Hence, there is still an unmet need in a minority of hypertensive patients. RDN is not the miracle cure that was promised [13], but may prove a solution in at least some of them. The challenge will be to identify those few high-risk patients who may benefit from RDN. Notably, in Symplicity HTN-3 [42••], while the distribution of blood pressure response has not been 
reported so far, analysis of pre-specified subgroups suggests that RDN may be superior to drug treatment alone in several instances, including age $<65$ years old and eGFR $>60 \mathrm{ml} / \mathrm{min} / 1.73 \mathrm{~m}^{2}[42 \bullet \bullet]$. These findings are consistent with analysis of the ENCOReD multicentre cohort, showing an inverse correlation between baseline plasma creatinine and blood pressure decrease after RDN [8].

Identification of determinants of response to RDN should be done within the context of properly designed randomised controlled trials and independent registries. Selection criteria should be much stricter than previously. Candidates to RDN should undergo an in-depth screening in order to rule out secondary and white coat hypertension. Elderly patients, patients with isolated systolic hypertension and altered renal function [8] are unlikely to respond, and should probably be excluded. Drug adherence should be assessed throughout the trial, using electronic pill monitoring, or preferably, drug dosages in plasma or urine. Completeness of RDN should be assessed using methods such as heart rate variability or electrical stimulation of renal arteries [80 ${ }^{\bullet}$. The primary efficacy endpoint should be based on ambulatory, not office, blood pressure. Indeed, ambulatory blood pressure is blinded by definition, and accordingly minimises white coat and placebo effects and physician-related biases. [54]. Furthermore, ambulatory blood pressure is an independent predictor of cardiovascular events, while after adjustment for conventional cardiovascular risk factors, office blood pressure has little added value $[54,81 \cdot]$. Office blood pressure measurement in patients blinded for treatment arm as in Symplicity HTN-3 [42••] is an alternative, but is much more complex, exposes patients from the control group to an unnecessary invasive procedure, and has a lesser predictive value than out-of-the office blood pressure measurements. Follow-up should be extended to several years, and primary endpoint for safety should be based on eGFR. The incidence of renal artery stenosis or stenosis progression should be evaluated by $\mathrm{CT}$ scan, which is the gold standard [82], or if contra-indicated, by MRI. In order to meet these requirements, we have designed the INSPiRED study [47]. Along with other ongoing trials such as REDUCE-HTN (NCT01570777), INSPiRED is expected to provide new, unbiased information on the efficacy and safety of RDN. Additional information may be derived from comparison of baseline characteristics of extreme-blood pressure responders versus poor or non-responders to the technique, as defined according to ambulatory blood pressure changes after RDN. This approach is currently being tested with the ENCOReD cohort [83].

\section{General Lessons}

RDN may find its place in the therapeutic arsenal of resistant hypertension and some other diseases characterised by sympathetic overactivity. It will never be a "miracle cure" of hypertension, or even the standard treatment for all patients with resistant hypertension [13, 44]. In this sense, and in this sense only, RDN has not met its expectations. The RDN "story" will remain a textbook case for methodologists, epidemiologists and sociologists interested in the process of medical discovery and dissemination of knowledge. They will try to understand how, in the 21 st century, shaky evidence derived from a few small trials with suboptimal design convinced a large majority of physicians, scientists and policy makers that RDN was ready for large scale clinical use, until announcement of the failure of a single large trial induced a radical and immediate opinion shift to an equally unmotivated radical mistrust [43].

Different factors have jointly contributed to the uncontrolled and premature deployment of RDN in Europe: (1) the attractive underlying rationale [79]; (2) the strong support of top-ranking experts of sympathetic system; (3) the enthusiasm of interventional cardiologists and radiologists looking for new areas of development in an era of "penury"; (4) the unrelenting pressure of industrials seeking new markets [84]; (5) the suboptimal management of resistant hypertension, both in Europe [7•] and the US [85]; (6) the lack of new drugs in the field of hypertension and the disinvestment of most drug companies from the hypertension field; (7) the "magic" effect of the word "resistant hypertension", which conveys the impression that affected patients are hopelessly exposed to a major risk of potentially fatal cardiovascular complications in the absence of new therapeutic options $[13,86]$; and (8) the lack of strict regulations for introduction of device therapies in Europe [13].

Thriving on what is viewed as the failure of RDN to meet its expectations, new treatment approaches of resistant hypertension such as electrical stimulation of baroreceptors [87] or creation of arterio-venous fistulas [88] are "knocking at the door". In order to avoid a rehearsal of the RDN story, several lessons need to be learned: (1) the most promising hypothesis, with the most solid underlying rationale should be tested using a rigorous methodology [44]; (2) hypertension specialists should be more united in order to deliver authoritative and independent advice and make the difference with industrials, policy makers and interventionalists; (3) the definition of resistant hypertension should be more stringent and primarily based on ambulatory blood pressure $[13,81 \bullet, 86]$; (4) methodological guidelines for state-of-the art evaluation of new drugs or device treatments of resistant hypertension should be proposed; (5) continued education programmes should help to improve management of resistant hypertension; and (6) new, more strict regulations for the introduction of medical devices in Europe are urgently needed. 


\section{Compliance with Ethics Guidelines}

Conflict of Interest Alexandre Persu, Yu Jin, Lotte Jacobs, and Jean Renkin declare that they have no conflict of interest.

Fadl Elmula Mohamed Fadl Elmula has received speaker honorarium from Medtronic and Hemo Sapiens.

Sverre Kjeldsen has received consultancy fees from Bayer, Medtronic, Serodus, and Takeda along with grants from Astra Zeneca and Pronova. Dr. Kjeldsen has also received honoraria payments from Astra Zeneca, Bayer, MSD, Medtronic, Novartis, and Takeda, along with royalty payments from Gyldendal.

Human and Animal Rights and Informed Consent This article does not contain any studies with human or animal subjects performed by any of the authors.

Open Access This article is distributed under the terms of the Creative Commons Attribution License which permits any use, distribution, and reproduction in any medium, provided the original author(s) and the source are credited.

\section{References}

Papers of particular interest, published recently, have been highlighted as:

- Of importance

-. Of major importance

1. Krum H, Schlaich M, Whitbourn R, et al. Catheter-based renal sympathetic denervation for resistant hypertension: a multicentre safety and proof-of-principle cohort study. Lancet. 2009;373:127581

2.• Esler MD, Krum H, Sobotka PA, Schlaich MP, Schmieder RE, Bohm M. Renal sympathetic denervation in patients with treatment-resistant hypertension (The Symplicity HTN-2 Trial): a randomised controlled trial. Lancet. 2010;376:1903-9. Despite its limitations and methodological biases, this small open randomised trial generated a huge wave of enthusiasm, with up to 15 to 20,000 renal denervations performed in Europe, until Symplicity HTN-3 disclosed that many of the apparent benefits of renal denervation may be explained by patient and physician-related biases.

3. Symplicity HTN-1 Investigators. Catheter-based renal sympathetic denervation for resistant hypertension: durability of blood pressure reduction out to 24 months. Hypertension. 2011;57:911-7.

4. Davis MI, Filion KB, Zhang D, et al. Effectiveness of renal denervation therapy for resistant hypertension: a systematic review and meta-analysis. J Am Coll Cardiol. 2013;62:231-41.

5. Savard S, Frank M, Bobrie G, Plouin PF, Sapoval M, Azizi M. Eligibility for renal denervation in patients with resistant hypertension: when enthusiasm meets reality in real-life patients. J Am Coll Cardiol. 2012;60:2422-4.

6. Verloop WL, Vink EE, Voskuil M, et al. Eligibility for percutaneous renal denervation: the importance of a systematic screening. $\mathrm{J}$ Hypertens. 2013;31:1662-8.

7. Persu A, Jin Y, Baelen M, et al. Eligibility for renal denervation: experience at 11 European expert centers. Hypertension. 2014;63: 1319-25. Analysis of 731 patients referred for renal denervation to 11 European expert centres. Careful screening and treatment adjustment removed indication of renal denervation in two-thirds of patients. The most frequent reason for ineligibility was blood pressure control after drug treatment adjustment in the expert centre.
8. Persu A, Jin Y, Azizi M, et al. Blood pressure changes after renal denervation at 10 European expert centers. J Hum Hypertens. 2014;28:150-6.

9. Fadl Elmula FE, Hoffmann P, Fossum E, et al. Renal sympathetic denervation in patients with treatment-resistant hypertension after witnessed intake of medication before qualifying ambulatory blood pressure. Hypertension. 2013;62:526-32.

10. Persu A, Azizi M, Burnier M, Staessen JA. Residual effect of renal denervation in patients with truly resistant hypertension. Hypertension. 2013;62:450-2.

11. Ezzahti M, Moelker A, Friesema EC, van der Linde NA, Krestin GP, van den Meiracker AH. Blood pressure and neurohormonal responses to renal nerve ablation in treatment-resistant hypertension. J Hypertens. 2014;32:135-41.

12. Mahfoud F, Ukena C, Schmieder RE, et al. Ambulatory blood pressure changes after renal sympathetic denervation in patients with resistant hypertension. Circulation. 2013;128:132-40.

13. Persu A, Renkin J, Thijs L, Staessen JA. Renal denervation: ultima ratio or standard in treatment-resistant hypertension. Hypertension. 2012;60:596-606.

14. Doumas M, Anyfanti P, Bakris G. Should ambulatory blood pressure monitoring be mandatory for future studies in resistant hypertension: a perspective. J Hypertens. 2012;30:874-6.

15. Azizi M, Steichen O, Frank M, Bobrie G, Plouin PF, Sapoval M. Catheter-based radiofrequency renal-nerve ablation in patients with resistant hypertension. Eur J Vasc Endovasc Surg. 2012;43:293-9

16. Weber MA, Black H, Bakris G, et al. A selective endothelinreceptor antagonist to reduce blood pressure in patients with treatment-resistant hypertension: a randomised, double-blind, placebo-controlled trial. Lancet. 2009;374:1423-31.

17. Vaclavik J, Sedlak R, Plachy M, et al. Addition of spironolactone in patients with resistant arterial hypertension (ASPIRANT): a randomized, double-blind, placebo-controlled trial. Hypertension. 2011;57:1069-75.

18. Bakris GL, Lindholm LH, Black HR, et al. Divergent results using clinic and ambulatory blood pressures: report of a darusentan-resistant hypertension trial. Hypertension. 2010;56:824-30.

19.• Howard JP, Nowbar AN, Francis DP. Size of blood pressure reduction from renal denervation: insights from meta-analysis of antihypertensive drug trials of 4,121 patients with focus on trial design: the CONVERGE report. Heart. 2013;99:1579-87. Based on a meta-analysis of antihypertensive drug trials of 4,121 patients with focus on trial design, the authors predicted that office blood pressure decrease after renal denervation would converge with that of ambulatory blood pressure - and thus substantially shrink - in a blinded randomised study. This dense paper contains many interesting thoughts about possible biases in an open randomised study such as Symplicity HTN-2.

20. Demaria AN. Reflections on renal denervation. J Am Coll Cardiol. 2014;63:1452-3.

21.• Fadl Elmula FE, Hoffmann P, Larstorp AC, et al. Adjusted drug treatment is superior to renal sympathetic denervation in patients with true treatment-resistant hypertension. Hypertension. 2014;63: 991-9. This carefully designed randomised study shows that, in patients with truly resistant hypertension and drug adherence demonstrated by drug witnessed intake, treatment adjustment is much superior to renal denervation.

22. Mancia G, Fagard R, Narkiewicz K, et al. 2013 ESH/ESC Guidelines for the management of arterial hypertension: the Task Force for the management of arterial hypertension of the European Society of Hypertension (ESH) and of the European Society of Cardiology (ESC). J Hypertens. 2013;31:1281-357.

23. Brandt MC, Mahfoud F, Reda S, et al. Renal sympathetic denervation reduces left ventricular hypertrophy and improves cardiac 
function in patients with resistant hypertension. J Am Coll Cardiol. 2012;59:901-9.

24. Brandt MC, Reda S, Mahfoud F, Lenski M, Bohm M, Hoppe UC. Effects of renal sympathetic denervation on arterial stiffness and central hemodynamics in patients with resistant hypertension. J Am Coll Cardiol. 2012;60:1956-65.

25. Ukena C, Mahfoud F, Spies A, et al. Effects of renal sympathetic denervation on heart rate and atrioventricular conduction in patients with resistant hypertension. Int J Cardiol. 2013;167:2846-51.

26. Himmel F, Weil J, Reppel M, et al. Improved heart rate dynamics in patients undergoing percutaneous renal denervation. J Clin Hypertens (Greenwich). 2012;14:654-5.

27. Tsioufis C, Papademetriou V, Tsiachris D et al. Drug-resistant hypertensive patients responding to multielectrode renal denervation exhibit improved heart rate dynamics and reduced arrhythmia burden. J Hum Hypertens 2014. doi:10.1038/jhh.2014.14

28. Mahfoud F, Cremers B, Janker J, et al. Renal hemodynamics and renal function after catheter-based renal sympathetic denervation in patients with resistant hypertension. Hypertension. 2012;60: 419-24.

29. Ott C, Mahfoud F, Schmid A, Ditting T, et al. Improvement of albuminuria after renal denervation. Int J Cardiol. 2014;173:311-5.

30. Mahfoud F, Schlaich M, Kindermann I, et al. Effect of renal sympathetic denervation on glucose metabolism in patients with resistant hypertension: a pilot study. Circulation. 2011;123:1940-6.

31. Hering D, Mahfoud F, Walton AS, et al. Renal denervation in moderate to severe CKD. J Am Soc Nephrol. 2012;23:1250-7.

32. Pokushalov E, Romanov A, Corbucci G, et al. A randomized comparison of pulmonary vein isolation with versus without concomitant renal artery denervation in patients with refractory symptomatic atrial fibrillation and resistant hypertension. J Am Coll Cardiol. 2012;60:1163-70.

33. Davies JE, Manisty CH, Petraco R, et al. First-in-man safety evaluation of renal denervation for chronic systolic heart failure: primary outcome from REACH-Pilot study. Int J Cardiol. 2013;162:189-92.

34. Witkowski A, Prejbisz A, Florczak E, et al. Effects of renal sympathetic denervation on blood pressure, sleep apnea course, and glycemic control in patients with resistant hypertension and sleep apnea. Hypertension. 2011;58:559-65.

35. Schlaich MP, Straznicky N, Grima M, et al. Renal denervation: a potential new treatment modality for polycystic ovary syndrome? J Hypertens. 2011;29:991-6.

36. Schmieder RE, Redon J, Grassi G, et al. ESH position paper: renal denervation - an interventional therapy of resistant hypertension. J Hypertens. 2012;30:837-41.

37. Schlaich MP, Schmieder RE, Bakris G, et al. International expert consensus statement: percutaneous transluminal renal denervation for the treatment of resistant hypertension. J Am Coll Cardiol. 2013;62:2031-45.

38. Ziegler AK, Bertog S, Kaltenbach B et al. Efficacy and safety of renal denervation in elderly patients with resistant hypertension. Catheter Cardiovasc Interv 2013. doi:10.1002/ccd.25166

39. Giordano A, Polimeno M, Messina S, et al. Transcatheter renal sympathetic denervation despite angiographically significant proximal stenosis: proof of concept from a case report. Int J Cardiol. 2014;172:224-5.

40. Bausback Y, Friedenberger J, Hertting K, et al. Renal denervation for hypertension refractory to renal artery stenting. J Endovasc Ther. 2014;21:181-90.

41. Pessina AC, Bisogni V, Fassina A, Rossi GP. Munchausen syndrome: a novel cause of drug-resistant hypertension. J Hypertens. 2013;31:1473-6.

42.• Bhatt DL, Kandzari DE, O'Neill WW, et al. A controlled trial of renal denervation for resistant hypertension. N Engl J Med. 2014;370:1393-401. In this large, US randomised trial including a sham procedure, the benefit assignable to renal denervation was found to be $<3 \mathrm{mmHg}$ vs. 25-30 mmHg in Symplicity HTN-2 and other previous studies. The most likely explanation accounting for this huge discrepancy is blinding, which minimised patient and physician-related biases in Symplicity HTN-3. The failure of Symplicity HTN-3 to meet its primary endpoint shows unequivocally that renal denervation is not ready for clinical dissemination.

43. Sapoval M, Azizi M. Renal artery denervation for the treatment of resistant hypertension. Update after Medtronic announcement that its Symplicity HTN3 study failed to meet its primary efficacy end point. Diagn Interv Imaging. 2014;95:353-4.

44. Myers MG, Wijeysundera HC. Renal Nerve Denervation-A Hypertension Bubble? J Clin Hypertens (Greenwich ) 2014. doi: $10.1111 /$ jch. 12334

45. Floras JS. Renal denervation for drug-resistant hypertension: suffering its original sin, seeking redemption. Can J Cardiol. 2014;30: 476-8.

46. Baker NC, Waksman R. Editorial: renal sympathetic denervation: a true lack of efficacy, or the victim of a "perfect storm"? Cardiovasc Revasc Med. 2014;15:61-2.

47. Jin Y, Jacobs L, Baelen M, et al. Rationale and design of the Investigator-Steered Project on intravascular Renal Denervation for Management of Drug-Resistant Hypertension (INSPiRED) trial. Blood Press. 2014:23:138-46.

48. Schirmer SH, Sayed MM, Reil JC, et al. Improvements in left ventricular hypertrophy and diastolic function following renal denervation: effects beyond blood pressure and heart rate reduction. J Am Coll Cardiol. 2014;63:1916-23.

49. Persu A, Renkin J, Asayama K, O'Brien E, Staessen JA. Renal denervation in treatment-resistant hypertension: the need for restraint and more and better evidence. Expert Rev Cardiovasc Ther. 2013;11:739-49.

50. Mahfoud F, Urban D, Teller D et al. Effect of renal denervation on left ventricular mass and function in patients with resistant hypertension: data from a multi-centre cardiovascular magnetic resonance imaging trial. Eur Heart J 2014. doi:10.1093/eurheartj/ ehu093

51. Geisler BP, Egan BM, Cohen JT, et al. Cost-effectiveness and clinical effectiveness of catheter-based renal denervation for resistant hypertension. J Am Coll Cardiol. 2012;60:1271-7.

52. Dorenkamp M, Bonaventura K, Leber AW, et al. Potential lifetime cost-effectiveness of catheter-based renal sympathetic denervation in patients with resistant hypertension. Eur Heart J. 2013;34:451-61.

53. Lambert GW, Hering D, Esler MD, et al. Health-related quality of life after renal denervation in patients with treatment-resistant hypertension. Hypertension. 2012;60:1479-84.

54. O'Brien E, Parati G, Stergiou G, et al. European society of hypertension position paper on ambulatory blood pressure monitoring. $\mathrm{J}$ Hypertens. 2013;31:1731-68.

55. Krum H, Schlaich MP, Sobotka PA, et al. Percutaneous renal denervation in patients with treatment-resistant hypertension: final 3-year report of the Symplicity HTN-1 study. Lancet. 2014;383:622-9.

56. Vonend O, Antoch G, Rump LC, Blondin D. Secondary rise in blood pressure after renal denervation. Lancet. 2012;380:778.

57. Kaltenbach B, Id D, Franke JC, et al. Renal artery stenosis after renal sympathetic denervation. J Am Coll Cardiol. 2012;60:2694-5.

58. Mabin T, Sapoval M, Cabane V, Stemmett J, Iyer M. First experience with endovascular ultrasound renal denervation for the treatment of resistant hypertension. EuroIntervention. 2012;8:57-61.

59. Bacaksiz A, Uyarel H, Jafarov P, Kucukbuzcu S. Iatrogenic renal artery stenosis after renal sympathetic denervation. Int J Cardiol. 2014;172:e389-90.

60. Jaén Águila F, Mediavilla Garcia JD, Navarro EM, Vargas Hitos JA, Fernandez-Torres C. Bilateral renal artery stenosis after renal denervation. Hypertension. 2014;63:e126-7.

61. Chandra AP, Marron CD, Puckridge P, Spark JI. Severe bilateral renal artery stenosis after transluminal radiofrequency ablation of 
renal sympathetic nerve plexus. J Vasc Surg 2014. doi:10.1016/j. jvs.2013.11.005

62. Kaiser L, Beister T, Wiese A, et al. Results of the ALSTER BP realworld registry on renal denervation employing the Symplicity system. EuroIntervention. 2014;10:157-65.

63. Raman B, Pathik B, Bridgman C. Recurrent pulmonary oedema after percutaneous radiofrequency renal denervation. Int J Cardiol. 2014; 174:e42-3.

64. Versaci F, Trivisonno A, Olivieri C, Caranci F, Brunese L, Prati F, Late renal artery stenosis after renal denervation: is it the tip of the iceberg? Int J Cardiol. 2014;172:e507-8

65. Versaci F, Trivisonno A, Olivieri C, Magri G, Caranci F, Prati F. Is an abnormal vascular response after renal sympathetic denervation predictive of permanent damage? An unusual case of late renal artery stenosis after energy delivery. J Endovasc Ther. 2014;21:191-6.

66. Worthley SG, Tsioufis CP, Worthley MI, et al. Safety and efficacy of a multi-electrode renal sympathetic denervation system in resistant hypertension: the EnligHTN I trial. Eur Heart J. 2013;34:2132-40.

67. Pucci G, Battista F, Lazzari L, Dominici M, Boschetti E, Schillaci G. Progression of renal artery stenosis after renal denervation. Impact on 24-hour blood pressure. Circ J. 2014;78:767-8.

68. Mann JF, Schmieder RE, McQueen M, et al. Renal outcomes with telmisartan, ramipril, or both, in people at high vascular risk (the ONTARGET study): a multicentre, randomised, double-blind, controlled trial. Lancet. 2008;372:547-53.

69. Mann JF, Schmieder RE, Dyal L, et al. Effect of telmisartan on renal outcomes: a randomized trial. Ann Intern Med. 2009;151:1-2.

70. Bakris GL, Sarafidis PA, Weir MR, et al. Renal outcomes with different fixed-dose combination therapies in patients with hypertension at high risk for cardiovascular events (ACCOMPLISH): a prespecified secondary analysis of a randomised controlled trial. Lancet. 2010;375:1173-81

71. Staessen JA, Wang J, Bianchi G, Birkenhager WH. Essential hypertension. Lancet. 2003;361:1629-41.

72. de la Sierra A, Segura J, Banegas JR, et al. Clinical features of 8295 patients with resistant hypertension classified on the basis of ambulatory blood pressure monitoring. Hypertension. 2011;57: 898-902.

73. Hayek SS, Abdou MH, Demoss BD, et al. Prevalence of resistant hypertension and eligibility for catheter-based renal denervation in hypertensive outpatients. Am J Hypertens. 2013;26:1452-8.

74.• Jung O, Gechter JL, Wunder C, et al. Resistant hypertension? Assessment of adherence by toxicological urine analysis. J Hypertens. 2013;31:766-74. Drug dosages in the urine show that up to $50 \%$ of patients with apparently resistant hypertension do not take or take only a few of the drugs prescribed. Changes in drug adherence may have a major impact on the apparent benefits of renal denervation, especially in observational and open randomised trials.

75. Rosa J, Zelinka T, Petrak $\mathrm{O}$ et al. Importance of thorough investigation of resistant hypertension before renal denervation: should compliance to treatment be evaluated systematically? J Hum Hypertens 2014. doi:10.1038/jhh.2014.3
76. Rimoldi SF, Scheidegger N, Scherrer U, et al. Anatomical eligibility of the renal vasculature for catheter-based renal denervation in hypertensive patients. JACC Cardiovasc Interv. 2014;7:187-92.

77. Claxton AJ, Cramer J, Pierce C. A systematic review of the associations between dose regimens and medication compliance. Clin Ther. 2001;23:1296-310.

78. Vrijens B, Vincze G, Kristanto P, Urquhart J, Burnier M. Adherence to prescribed antihypertensive drug treatments: longitudinal study of electronically compiled dosing histories. BMJ. 2008;336:1114-7.

79. Esler M. Renal denervation for hypertension: observations and predictions of a founder. Eur Heart J. 2014;35:1178-85.

80. Chinushi M, Izumi D, Iijima K, et al. Blood pressure and autonomic responses to electrical stimulation of the renal arterial nerves before and after ablation of the renal artery. Hypertension. 2013;61:450-6. In the animal, electrical stimulation of renal arteries elicits a sympathetic reaction that is abolished by renal denervation. This approach may prove helpful to evaluate completeness of renal denervation and predict blood pressure response to renal denervation in man.

81. Persu A, O'Brien E, Verdecchia P. Use of ambulatory blood pressure measurement in the definition of resistant hypertension: a review of the evidence. Hypertens Res 2014. doi:10.1038/hr.2014.83. This review summarises the evidence in favour of the superiority of ambulatory over office blood pressure for the diagnosis of resistant hypertension. Ambulatory, not office, blood pressure should be used in trials testing new drugs or interventions in patients with resistant hypertension, both for patients selection and treatment evaluation

82. Pellerin O, Sapoval M, Trinquart L, et al. Accuracy of multidetector computed tomographic angiography assisted by postprocessing software for diagnosis atheromatous renal artery stenosis. Diagn Interv Imaging. 2013;94:1123-31.

83. Persu A, Azizi M, Jin Y et al. Hyper-responders vs non-responder patients after renal denervation : do they differ? J Am Soc Hypertens 2014;8(4), Supplement: e117

84. Stamatakis E, Weiler R, Ioannidis JP. Undue industry influences that distort healthcare research, strategy, expenditure and practice: a review. Eur J Clin Investig. 2013;43:469-75.

85. Hanselin MR, Saseen JJ, Allen RR, Marrs JC, Nair KV. Description of antihypertensive use in patients with resistant hypertension prescribed four or more agents. Hypertension. 2011;58:1008-13.

86. Campese VM. Interventional hypertension: a new hope or a new hype? The need to redefine resistant hypertension. J Hypertens. 2013;31:2118-21.

87. Bisognano JD, Bakris G, Nadim MK, et al. Baroreflex activation therapy lowers blood pressure in patients with resistant hypertension: results from the double-blind, randomized, placebo-controlled rheos pivotal trial. J Am Coll Cardiol. 2011;58:765-73.

88. Brouwers S, Dolan E, Galvin J, et al. Creation of an iliofemoral arteriovenous fistula in patients with severe hypertension: a prospective open label multi-center pilot study. J Hypertens. 2013;31(e-supple A):e103. 